\title{
Seismic Vulnerability Assessment of Existing Buildings in Downtown Yangon, Myanmar
}

\author{
A. Hnin Ei Win ${ }^{1}$ and A. Saw Htwe Zaw ${ }^{2}$ \\ ${ }^{1}$ Yangon City Development Committee, Myanmar \\ ${ }^{2}$ Yangon Technological University, Myanmar
}

\begin{abstract}
An existing building management system is requisite and important for present modernized society and urbanization. The potential problems cause the falling down of infrastructure and defiency of environmental consistency through the impact of earthquake. On this basic requirement, the study on vulnerable buildings due to the likely earthquake impact highlights the performance evaluating of earthquake-resistant building quality and the effectiveness of existing infrastructure standard, and the compulsory facts and factors for facilitated decision making solutions. This paper is focusing to reflection and influence of existing buildings mitigation on the risk of earthquake impact in Yangon.
\end{abstract}

\section{Introduction}

It is related earthquake risk with seismic hazard, buildings vulnerability and exposure. Generally, the seismic hazard specifies micro seismic intensity, peak ground acceleration and its annual probability of exceedance at a site. The probability of destruction and loss states the impact of earthquake in terms of buildings vulnerability. The principal objective of a seismic vulnerability assessment is to estimate the probable level of damage and evaluate the performance measure. Furthermore, in order to overcome the potential risk of high magnitude earthquake, a vulnerability assessment must be performed. Risks of earthquake are dangerous, destructive and unpredictable occurrence that can be mitigated by reinforcing the performance of existing vulnerable buildings as a result of vulnerability assessment. With the advantage of geographical information system (GIS) and Rapid Visual Screening Method (RVS), it can significantly be demonstrated buildings information and retrofitting challenge for vulnerable buildings in order to prevent loss of lives, property and safety.

\subsection{Earthquake and Myanmar}

It is situated in South East Asia region and consisting of 14 states and divisions with estimated 60 million total population. Usually, in Myanmar, earthquakes happen by Alpide Seismo Tetonic Belt that is the second most seismically active catastrophe region after the circum-Pacific belt. The result of northward movement of the two well-known Burma plate and India plate cause subduction earthquake resulting of India plate underneath the former plate at the average 4 to $6 \mathrm{~cm}$ yearly along the Andaman Mega-thrust zone. . In addition, the northward moving of the Burma Plate from the spreading centre in the Andaman Sea at an average rate of 2.5 to $3 \mathrm{~cm}$ per year. The Burma plate is a minor tectonic plate and considered as a larger part of Eurasian Plate. The movement of Burma Plate causes the Sagaing and related faults which makes happening major earthquakes in Myanmar. Therefore these two tectonic behaviours and the sources of earthquake noticeably mention that Myanmar is an earthquake prone country as seen in Fig.1 

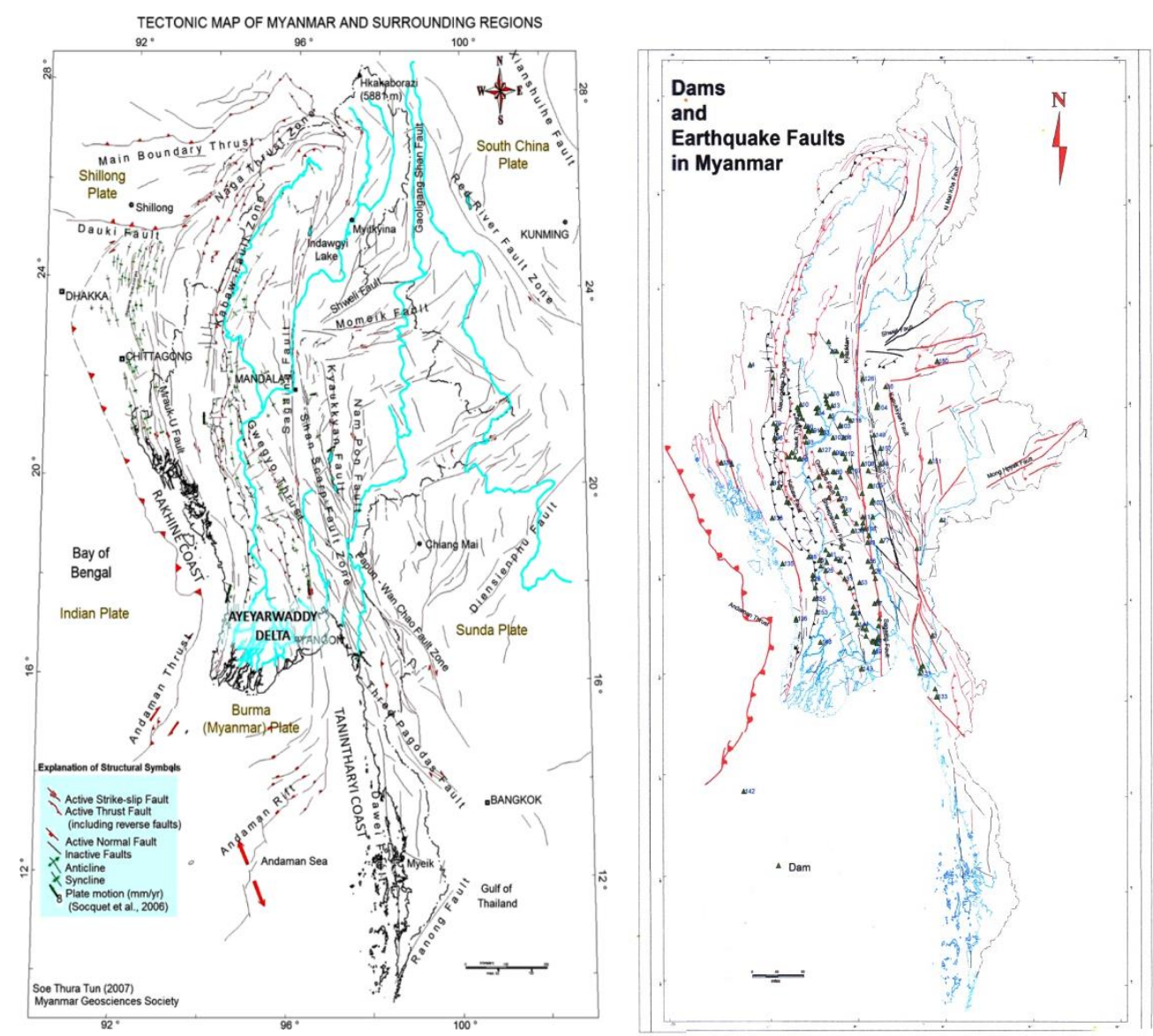

Fig. 1. Faults of Myanmar

Moreover, the active Sagaing fault is present from the North to South passing through the whole central Myanmar. The Sunda subduction mega thrust zone trends off-shore Southwest and west of the Myanmar coast and on-land to the west and Northwest of Myanmar. Besides, the north-eastern part of Myanmar is continuously bounded with southern Yunnan earthquakes. These are wellknown earthquake risk characteristics which results the seismic zone map of Myanmar has been developed in 2006 (Thein and Swe 2006) as shown in Fig.2. 

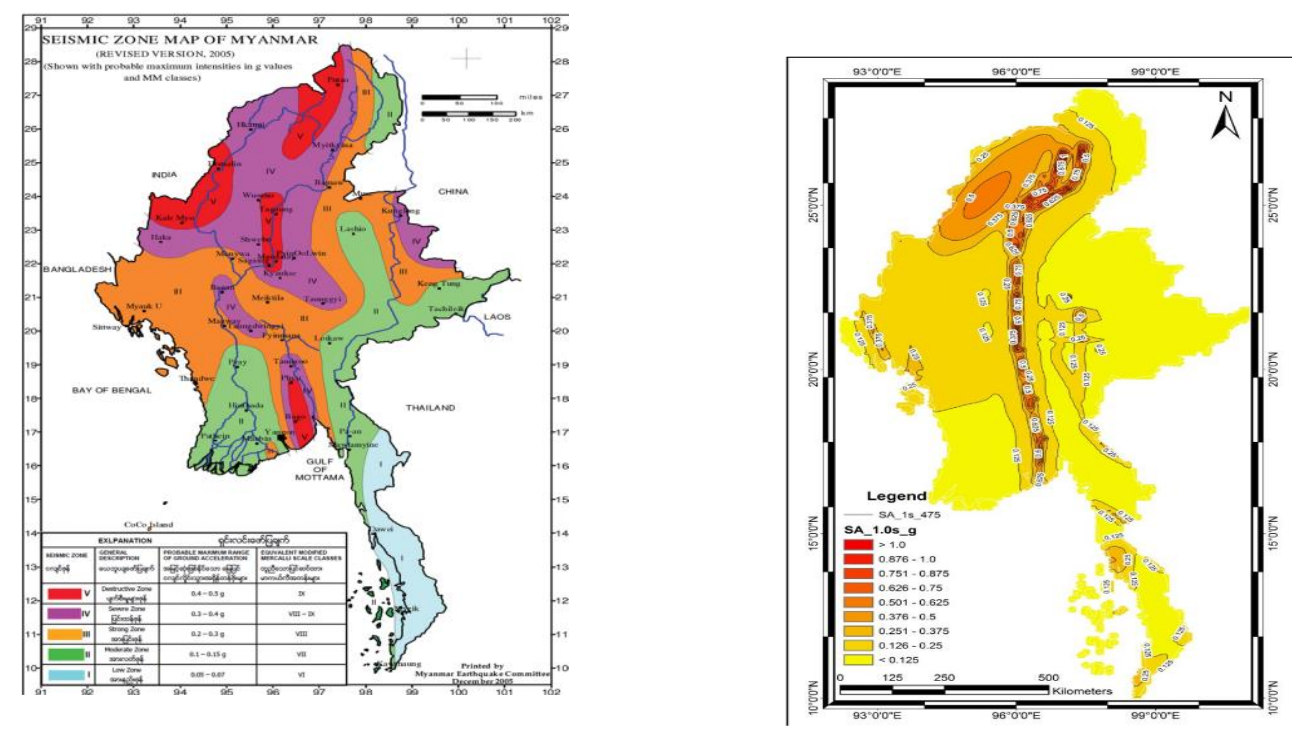

Fig. 2. Seismic Risk Zone of Myanmar

\subsection{Earthquake and Buildings}

It is said to be "earthquake does not kill people but the buildings do ". Therefore, the major impact of element of loss in an earthquake is buildings destructibility which impacts mainly affected to the people. Moreover, the loss of lifelines property threatens to the health, social, safety and the life quality of the people. Because of this, safe building structures are important and needed to be focus of risk management. There are two components in building structures such are structural and non-structural. The former defines main load bearing elements such are columns, beams, footings and load bearing walls. Architectural and design features e.g. ceiling, billboards, parapets, doors, windows, etc., and decorated items and services like mechanical, electrical and plumbing fixtures. Both components are required to be strong enough to resist seismic impact for not happening the loss of lives due to the collapse and or damage of buildings.

The physical vulnerability assessments of buildings encourage the positive impact to the entire risk management strategies. In case of earthquake, the vulnerable buildings may cause fatalities and loss of political stability, economical situation and secure emotional state. Therefore, in order to scope the human building capacity, the specific information of building existing physical condition is essential. Furthermore, assessing the vulnerability of buildings is the basic requirement for not only disaster mitigation, prevention and rehabilitation process but also for urbanization development. It will be also beneficial for measuring building construction management policy and guideline municipalities' information. The information of buildings typology, shape and size, constructed year, physical damage conditions, risk factors etc. represent a major role in risk management.

\subsection{Relevance of Study}

The Sagaing Fault is the most active fault among numerous faults and thrusts in Myanmar and it is also the most earthquakes occurred along the fault. It is supposed that there might be huge earthquake occurring possibly and unexpectedly. Since Yangon is just $35 \mathrm{~km}$ far from the Sagaing Fault, it is assumed to be the most dangerous earthquake impact and big loss. Taking consideration upon the vulnerability of existing buildings and infrastructures represents the most vital role of seismic mitigation procedures. For earthquake 
safety buildings, the vulnerable buildings assessment should be analyzed. Furthermore, buildings information and database are needed for not only the building code development, new construction projects policy making, upgrading the urban requirements but also technical concerns. Concerning the present buildings conditions does much support the increasing of the existing buildings sustainability. In addition, the use of buildings vulnerable appraisal assessment data can be effective and efficient in retrofitting process, rehabilitation efforts, relief, rescue and reconstruction planning and regulatory framework of local authority involvement for providing urban development, infrastructure services and regulation process. The study of this assessment is directly related with the number of possible fatalities. Moreover, the use of this study can reduce much of time and effort in data collection for urban development planning, services providing planning, the regulated construction involvement, regulatory framework planning and safer living environment strategy.

\subsection{Objective and Scope of Study}

It is aimed to develop the building vulnerability assessment by using rapid visual screening method of building survey data of individual buildings, to provide and evaluate an overall view of vulnerable buildings in downtown Yangon for seismic risk, to identify and describe building information for implementing a wide range of best practice control strategies in construction projects and mandated standards and to determine building vulnerability and describe visual damage for pre and pose disasters planning strategies as well as education systems, and to raise awareness among the public, government and the community.

The scope of study includes preliminary survey information such as address, building type, occupancy, no. of stories, estimated population and the age of the buildings, data collection is taken to be filled into the assessment, identify and evaluate the earthquake risk resistant building performance quality depending on the rapid visual screening inspection database, estimation of potential level of risk in downtown area.

\subsection{Research Limitation}

The primary data collection survey takes much time and it is not available such number of housing data in municipal authority. Moreover, the building attributes cannot be found in some areas and it is impossible to investigate the household unit of each building. Furthermore, due to the visual inspection methodology, the building type at the outer appearance unreinforced masonry building; however, there might be steel structure building inside. In case damage component analysis is impossible in a very short time, or it can be done by outside of the buildings, the posting rate regarded might be confusing. However, this study is completely ensured to support the database of vulnerable building assessment.

\section{Literature Review}

\subsection{Seismic Hazard}

Seismic risk has been determined by the combination of seismic hazard, vulnerability and exposure. It as well can be defined as the estimated consequences of hazardous phenomenon at a specific period of time. The expected damage and estimated loss are included in the seismic risk assessment. Therefore, the seismic risk plays vital role as a concrete 
foundation of risk mitigation planning, decision making policies and strategies. It can be expressed simply in the mentioned form below in terms of buildings damage and expected loss after an earthquake.

\section{Seismic Risk =Hazard $\mathrm{x}$ Vulnerability $\mathrm{x}$ Exposure}

Though seismic hazard cannot be evitable, risk can be lessened by enhancing in structure response mechanisms. The greater the seismic hazard, the more possible seismic risks will be occurred at a given time interval. However, the degree of vulnerability and the utilities are able to be controlled by improving capabilities of basic infrastructure so that the seismic risk can be reduced.

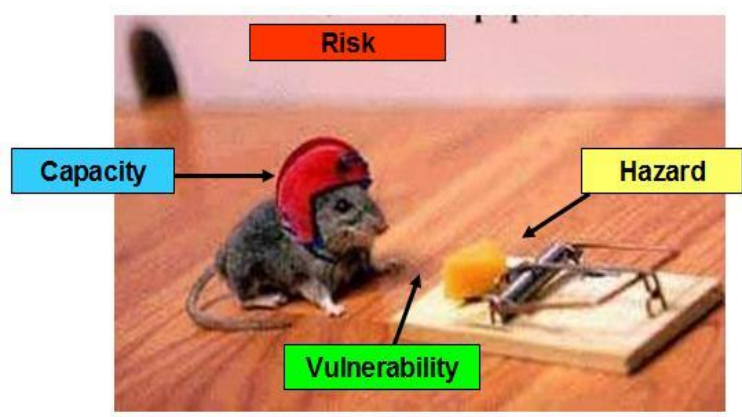

\subsection{Seismic Hazard}

Fig. 3. Seismic Risk

The seismic hazard generally defines the potential seismic ground motion as fault supture exceeding certain intensity, magnitude of peak ground acceleration. The level of the seismic hazard is determined by the presence of potential dangerous seismic zones. It has been studied a view to zonation or micro zonation in order to evaluate earthquake magnitude, amplification phenomenon and useful data for urban development planning. There may be two approaches: deterministic or probabilistic for hazard assessment. The deterministic method is based in the observed damage and rehabilitation scenarios during or after the seismic events. The latter method quantifies the seismic activity level and the effects in the affected area with respect to the epicentre.

\section{Data Collection}

It followed FEMA $154 \mathrm{P}$ (Handbook of Rapid Visual Screening of Buildings for Potential Seismic Hazards, $2^{\text {nd }}$ Edition, 2002. Though R.V.S is visual inspection, it can predict the existing conditions of buildings to the most accurate and economy studies, and the outcome can be stated clearly. It is widely used since 1988 by local communities and authorities in order to identify building information how much strong enough to resist seismic impact. For the hazardous building mitigation development program, RVS surveyed data is the basic reference and quick assessment. There are three steps for vulnerability assessment: rapid visual screening assessment, preliminary vulnerability assessment and detailed vulnerability assessment. In this study, R.V.S assessment of seismic risk is taken account as a 
foundation database for finding out buildings management and disaster mitigation program.

\subsection{General Information}

According to the level of seismic risk, there are several significant methods of evaluating the seismic risk zone; it involves the level of seismic hazard, the population and the amount of vulnerable structures. As Myanmar lies in a tectonically active region, major active faults and fault systems are present almost all parts of the country. The studied area is present in seismic zone map of 2B which means the seismic intensity is moderately high. In fact of the seismic characteristics, the seismic damage depends on not only the ground movement but the three main basic factors; earthquake characteristics, site characteristics, structural characteristics should be considered. The process to identify potential seismic sources in Myanmar was led by the Myanmar Earthquake Committee (MEC).

Table 1. Approximate Code Maximum Zone Acceleration and Magnitude

\begin{tabular}{|l|l|l|}
\hline Zone & Maximum Acceleration & Maximum Magnitude \\
\hline 0 & $0.04 \mathrm{~g}$ & 4.3 \\
\hline 1 & $0.075 \mathrm{~g}$ & 4.7 \\
\hline $2 \mathrm{~A}$ & $0.15 \mathrm{~g}$ & 5.5 \\
\hline $2 \mathrm{~B}$ & $0.2 \mathrm{~g}$ & 5.9 \\
\hline 3 & $0.3 \mathrm{~g}$ & 6.6 \\
\hline 4 & $0.4 \mathrm{~g}$ & 7.2 \\
\hline
\end{tabular}

According to maximum seismic zone, it is known how much the earthquake magnitude could be impacted the considered area.

Table 2. Relationship between Earthquake Magnitude and Intensity

\begin{tabular}{|c|c|c|c|}
\hline $\begin{array}{c}\text { Earthquake } \\
\text { Magnitude }\end{array}$ & $\begin{array}{c}\text { Maximum } \\
\text { expected } \\
\text { Intensity }\end{array}$ & $\begin{array}{c}\text { Radius of } \\
\text { area where felt } \\
(\mathrm{Km})\end{array}$ & $\begin{array}{c}\text { Size of area } \\
\text { where felt }(\mathrm{Km} \\
\text { Sq. })\end{array}$ \\
\hline $4.0-4.9$ & IV $\sim$ V & 50 & 7,700 \\
\hline $5.0-5.9$ & VI VII & 110 & 38,000 \\
\hline $6.0-6.9$ & VII $\sim$ VIII & 200 & 125,000 \\
\hline $7.0-7.9$ & IX $\sim$ X & 400 & 500,000 \\
\hline $8.8-8.7$ & XI XII & 800 & $2,000,000$ \\
\hline
\end{tabular}

Since the $18^{\text {th }}$ century, at least 15 major earthquakes including events in 1762 (Northern Rakhine Coast) and 1839 (Innwa Ancient Capital) occurred in Myanmar territory. Recent earthquakes occurring in Central Myanmar with notable magnitudes include the 1975 Bagan earthquake (Magnitude 6.5), the 2003 Taungdwingyi earthquake (Magnitude 6.8) and the 2011 Tarlay earthquake (Magnitude 6.8). The occurrence of past earthquake history and its casualties are considered providing the source by the department of Metrology and Hydrolody.

\subsection{Building Typology}


The research areas of 4 townships; Kyauktada township, Pabedan Township, Lathar Township and Lamataw Township are one of the central business district areas (downtown areas) of Yangon, Myanmar. The studied area coverage are residential apartments, commercial buildings and the rest are government offices, schools and religious structures. Thus survey was just only focused on earthquake issues so that identifying be constructed year of buildings, building type, approximate plot area of the buildings, features of buildings, occupancy and damage state are included. Hence, these accumulated data are able to be taken in the vulnerable analysis of FEMA 154 Tier-1 updated in 2002. The most common types found in the area are $\mathrm{W} 1, \mathrm{C} 1, \mathrm{C} 2, \mathrm{C} 3$, URM and BN1.

\subsubsection{W1 Building Type}

It is light wood frame single or multiple family dwellings of one or more stories in height. It can be mostly found as primary schools, secondary schools and high schools. It can be observed the structures are wooden post and beams and timber plank walls might be included.

\subsubsection{C1 Building Type}

It is concrete moment resisting frame construction type and consists of concrete beams and columns for resisting both lateral and vertical forces. The basic configuration of such building type is the presence or absence of ductility details. Ductile detailing demonstrates to the presence of special steel reinforcing within concrete beams and columns that support the structural performance beyond the elastic limit in bending. For the Rapid Visual Screening (R.V.S) procedures survey, it can be said that all concrete moment resisting frames are concrete and not ductile steel frames. Thus, lack of non-ductile concrete members result brittle failure to buildings fall down. These types of building structures are mostly found in common in Yangon.

\subsubsection{C2 Building Type}

It is a concrete shear wall building construction type which the shear walls are normally located along the perimeter or part of perimeter or around the lift service core. Comparing with the load bearing masonry wall structures, the wall thickness of concrete bearing wall varies 6 to 10 inches.

\subsubsection{C3 Building Type}

This type of buildings is concrete frame with unreinforced masonry infill category. It can be observed where unreinforced masonry buildings construction is being used. The concrete columns and beams are relatively large. The masonry is not covered in some buildings. Yet, in the case of exposing the decorated walls, the infill material is difficult to be determined whether URM or a thin concrete masonry infill. These types of buildings are normally used for residential buildings. 
Unreinforced masonry buildings (URM) are built in around the year 1900s. The walls consisted are definitely load bearing walls with either wood or slab floor construction type. Mostly, the wall thickness of URM building type is typically thick and sometimes it would be performing the $\mathrm{H}$-beam loading and there always needed to be checked joints. It is the most dangerous and hazardous structural type because of inadequate shear resistance, weakness of anchorage and much deflection of diaphragm. However, these types of buildings are common in 1900's and they had experience for highly impact earthquake.

\subsubsection{BN1 Building Type}

It refers to the brick noging building type with respect to the good conditions. Usually, the main skeleton structure is constructed with timber and filled with brick as walling. This type of buildings mostly found as religious buildings of each and every quarter. The religious buildings are some kind of assembly function.

\subsection{Building Identification Information}

It involves the number of stories, building constructed year, building occupancy, soft story vertical irregularity, plan irregularity, heavy overhang, short column effect, pounding impact and soft soil consideration. Normally, the height of story at ground floor level must be at least 10 feet and the rest of each storey height is a feet minimum according to the municipal by laws. However, the ground floor level height of older buildings is usually 14 feet high. Depending on the height of structure, the certain amount of damage possibility can be determined. Furthermore, the expectancy of buildings life time is the key characteristics consideration in seismic vulnerability assessment. It is as well concerned with buildings structure design, construction methodology, materials, and construction practices and guidelines usage.

In order to classify the age of buildings, there are divided into three main categories of buildings constructed year: the year before 1980, the year between 1980 and 2003, and the year after 2003 until 2017. The majority of existing buildings built before 1980 are unreinforced masonry buildings and in which period, there was not implemented seismic structural design. Moreover, some of the buildings had suffered World War II impact and most existing building is regarded as heritage structures. The construction method of colonial time is clearly demonstrated and the construction material used is able to be studied in practice. During the year 1980 and 2003, the construction industry is so much booming in Yangon City. Because of the changing lifestyles and urbanization pattern: population density shifted from rural to urban, the housing requirements demand was increasing rapidly. However, poor regulatory guidelines and inspection in situ, in efficient construction method and technology, and ethnically misstates and errors of developers might reduce some of the buildings quality and threaten as dangerous, unsafe and dissatisfactory condition.

After the year 2003 until 2016, the seismic detailing structural design must be encouraged for new construction projects by municipal authority. Since 
the committee of quality control of high-rise projects (CQHP) was founded in 2003, all new buildings are not permitted to build unless seismic design is included. Therefore, the age of buildings are different based on the above mentioned year interval.

The building usage or occupancy indicates the number of people in the building and the degree of importance of the building. According to FEMA 154, there are 9 categories of building occupancy such are assembly, commercial, office, emergency services, government, schools, residential, warehouses and shelter. In this survey, the occupancy type of historic is added to be taken account because these are $20 \%$ of the total number of historic buildings present in this studied area.

Besides, the shape of buildings, well connections and the size of overhangs, the adjacent buildings impact and the classification of soft soil stand vital roles together in this assessment.

\subsection{Analysis Procedures}

The performance score or R.V.S score can be analysed by buildings parameter, such are building type, occupancy, year built, features and damage area assessment. In order to obtain R.V.S score followed by the preliminary location map, draft building layout plan, calculation score and the implementation of vulnerable buildings by GIS.

$$
\mathrm{PS}=\mathrm{BS}+\Sigma \mathrm{SM}
$$

Where, PS = performance score

$\mathrm{BS}=$ base score

$\mathrm{SM}=$ score modifier

\subsection{Limitations of Analysis}

According to the hazard map, the research area is situated in moderately high seismicity. Thus, regarding to R.V.S data collection form of FEMA $154 \mathrm{P}$, in case of consideration the score modified factor of falling hazard and heavy overhang are not available. It is assumed to be -0.2 in analysis. Furthermore, the population of each unit cannot achieve, it would be a weakness to consider the effect of loss of lives.

\section{Analysis and Results}

In this study, six types of typical existing buildings; wood frame, masonry reinforced concrete, concrete shear wall, concrete brick infill, unreinforced masonry and brick nogging buildings are represented as the proposed buildings. The proposed buildings are the existing representative building types in downtown 4 Townships, Yangon. The score calculation and result are shown as below. 


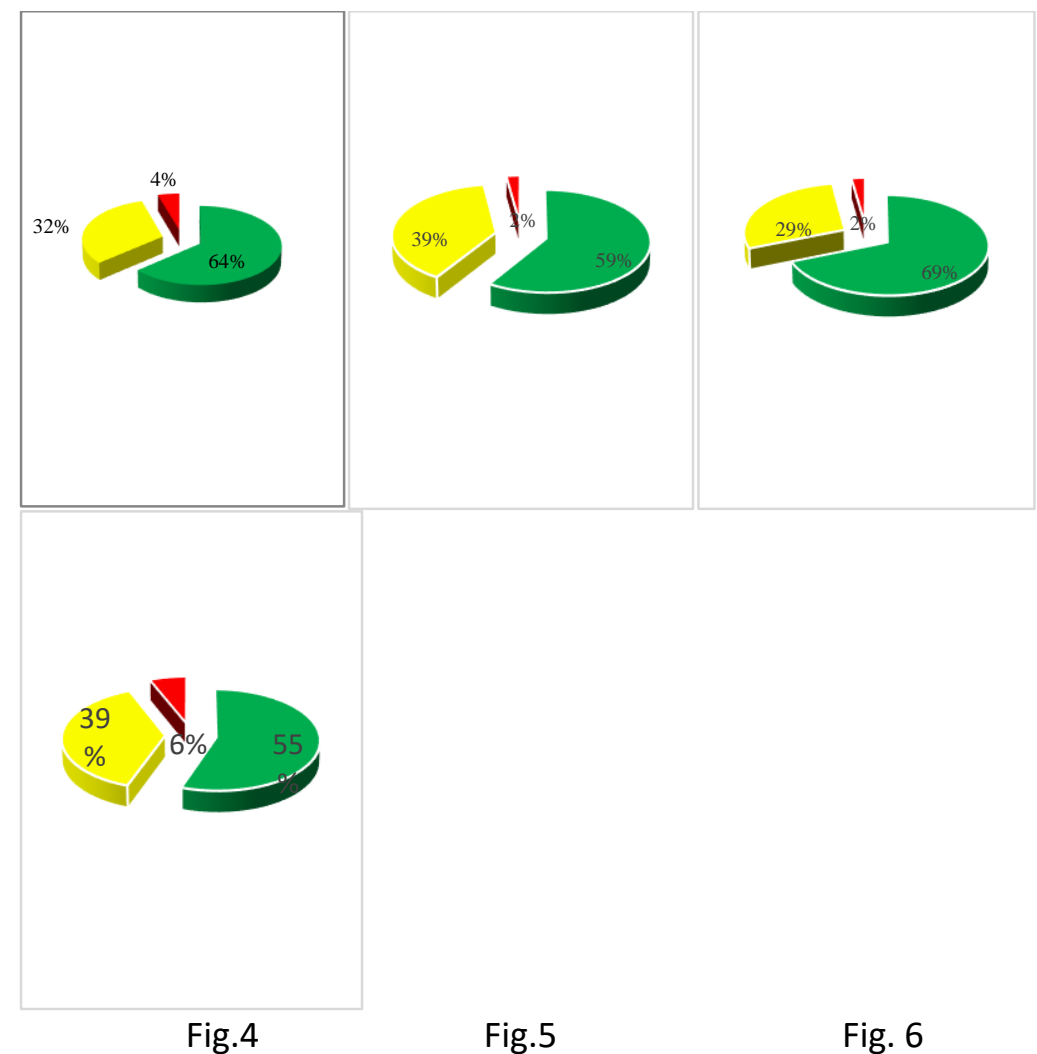

Fig.7

Fig. 4. Building Vulnerability alarm state of Kyauktada Township Fig. 5. Building Vulnerability alarm state of Pabedan Township Fig 6. Building Vulnerability alarm state of Lanmadaw Township Fig 7. Building Vulnerability alarm state of Lathar Township

It is obviously seen that the percentage of red portion is much less compared with the other two which represents the most vulnerable buildings are found in those 4 townships. However, it does not mean the red buildings alarming the risk at fall down and only intended to state that they are required to be strengthened as possible. The yellow color represents the earthquake resistance building performance needed to be strong enough by retrofitting. 


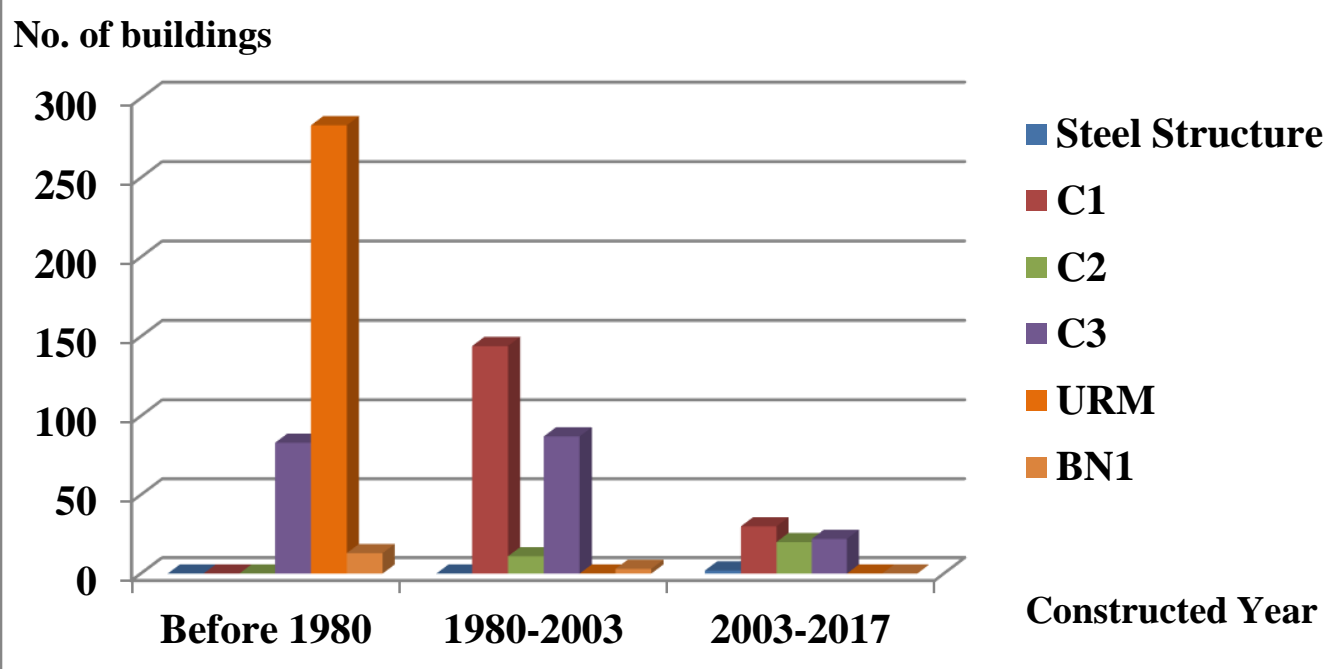

Fig. 8. Number of Buildings constructed in respective period in Kyauktada Township

Referring to the above mentioned fig. it is found that there are numerous unreinforced masonry buildings before 1980 and most of which were constructed in colonial time. The brick noggin building types are rarely found after 1980s whilst the steel structure building technology has been introduced after 2003. Though the score calculation for steel structure is not provided in FEMA $154 \mathrm{P}$, it is assumed to be $\mathrm{C} 1$ structure type.

\section{Conclusion and Recommendations}

The seismic vulnerability assessment of existing buildings in downtown Yangon highlights the building performance of current condition. Moreover, it demonstrates the gap between the regulatory bodies and the existing buildings for strengthening purposes. There has limitation in analysing the assessment due to the time and financial constraint as well as technical assistant for preceding the further steps such are detailed assessment for tier 2 and tier 3 as per FEMA $154 \mathrm{P}$.

There also need to be considered retrofitting guidelines for prototype and vulnerable buildings. It encourages municipal authorities to establish the rules and regulations for existing buildings sustainability.

\section{References}

1. FEMA 154 P (Handbook of Rapid Visual Screening of Buildings for Potential Seismic Hazards, $2^{\text {nd }}$ Edition, 2002. 